\title{
CORRIGENDUM
}

\section{Development of bioelectrical impedance-derived indices of fat and fat-free mass for assessment of nutritional status in childhood}

CM Wright, A Sherriff, SCG Ward, JH McColl, JJ Reilly and AR Ness

European Journal of Clinical Nutrition (2008) 62, 686; doi:10.1038/ejcn.2008.31

Correction to: European Journal of Clinical Nutrition (2008) 62, 210-217; doi:10.1038/sj.ejcn.1602714

Since the publication of this article, the authors have identified a correction to equation 3 on page 212. The equation should read:

Fat free mass $=\left(\left(\rho *\left(\right.\right.\right.$ height $\left.\left.\left.^{2} / Z\right)+c 1\right) / h\right)+c 2$
We have now added additional parentheses to the equation for clarity. We can confirm that the correct formulation of the equation was used in all analyses to produce indices of fat and fat-free mass.

The authors would like to apologize for this error. 